Research Article

\title{
Bearing Capacity of Recycled Self-Compacting Concrete-Filled Circular Steel Tubular Long Columns Subjected to Axial Load
}

\author{
Feng Yu $\mathbb{D},{ }^{1,2,3}$ Jie Song $\mathbb{D}^{2},{ }^{2}$ Shuangshuang Bu $\mathbb{D},{ }^{2}$ Jingfeng Wang $\mathbb{D}^{4},{ }^{4}$ Haiying Wan $\mathbb{D}^{4},{ }^{4}$ \\ Wanyu Shen $(\mathbb{D}){ }^{5}$ Wei Huang $(\mathbb{D})^{2}$ and Yuan Fang ${ }^{2}{ }^{2}$ \\ ${ }^{1}$ State Key Laboratory of Building Safety and Built Environment, Beijing 100013, China \\ ${ }^{2}$ Department of Civil Engineering and Architecture, Anhui University of Technology, Ma'anshan 243032, Anhui, China \\ ${ }^{3}$ National Engineering Research Center of Building Technology, Beijing 100013, China \\ ${ }^{4}$ College of Civil Engineering, Hefei University of Technology, Hefei 230009, China \\ ${ }^{5}$ Technology Center, Anhui Fuhuang Steel Structure Co. Ltd., Chaohu 238076, China \\ Correspondence should be addressed to Shuangshuang Bu; biluo12345@163.com
}

Received 22 April 2021; Revised 6 August 2021; Accepted 1 September 2021; Published 29 September 2021

Academic Editor: Claudio Mazzotti

Copyright (c) 2021 Feng Yu et al. This is an open access article distributed under the Creative Commons Attribution License, which permits unrestricted use, distribution, and reproduction in any medium, provided the original work is properly cited.

\begin{abstract}
To investigate the ultimate bearing capacity and deformation of the recycled self-compacting concrete-filled circular steel tubular (RSCCFCST) long columns subjected to axial load, nine specimens with different recycled self-compacting concrete (RSCC) strength grades and slenderness ratios are tested. The experimental results indicate that the lateral deflection dominates the buckling failure of the specimens. The ultimate bearing capacity of the specimens is enhanced gradually as the RSCC strength grade increases but decreases as the slenderness ratio rises. The load-strain curves are linear and basically coincide at the elastic stage. The decrease in the slenderness ratio or increase in the RSCC strength grade contributes to the improvement of the stiffness and ultimate circumferential and axial strains of the columns gradually. Based on the combined tangent modulus theory and bearing capacity of the RSCCFCST short columns, two estimation models are presented to predict the ultimate bearing capacity of the RSCCFCST long columns. Additionally, comparisons between the calculation results of the ultimate strength demonstrate that the prediction models established in this study are more accurate than the other specifications mentioned.
\end{abstract}

\section{Introduction}

With the economic development and urbanization over the last decades, a huge amount of construction and demolition wastes was generated. There are 40 countries in the world whose annual construction and demolition waste production exceeds 3.0 billion tons until 20 . In China, almost 1.6-1.8 billion tons of construction and demolition waste is produced every year. Those wastes have caused a series of problems, such as the occupation of arable land and pollution of environment $[1,2]$. As a main component of construction and demolition wastes, the recycling of the waste and demolished concrete has become an indispensable part of the ecological civilization construction, which has been focused on all over the world $[3,4]$.
It has been proved that recycled aggregate (RA) from waste concrete can be effectively used to obtain RA products used in buildings [5-7]. Recycled aggregate concrete (RAC) is mainly made of recycled aggregate, partially or completely replacing natural aggregates. Thomas [8] and Dimitriou [9] found that the failure mode of RAC was similar to the ordinary concrete, and the compressive strength of RAC can be improved by adjusting the water-to-cement ratio and optimizing the mix ratio. Laserna [10] pointed out that the elastic modulus and compressive and tensile strength of RAC decreased with the increase of the replacement rate of RA. Some scholars conducted experiments and illustrated that the mechanical properties of RAC prepared by modified RA were better than those of ordinary concrete [11-13]. Limbachiya [14] also illustrated that the durability of RAC can be improved by adding an appropriate amount of fly- 
ash. Xiong et al. $[15,16]$ investigated the static and dynamic bond behaviors of RAC with BFRP bars and proposed the constitutive model simulating the bond stress-slip relation and formulae for predicting the dynamic bond performance, which provide the basis for the design.

Concrete-filled steel tube (CFST) structures take full mechanical advantages of the concrete and steel, which has high strength and good ductility. Numerous studies on CFST have been carried out and plenty of achievements have been made [17-21]. Recycled concrete-filled steel tube (RCFST) is a special kind of CFST which is filled with RAC. Research conducted by Chen et al. [22] on the properties of the normal RCFST strength under combined loading indicated that the effects of the slenderness ratio, eccentricity, and steel ratio on the performance of RCFST columns were analogous to the CFST. Li et al. [23] experimentally examined the behaviors of the RCFST columns subjected to higher elevated temperature and revealed that improving the impact strength of the RCFST columns by increasing the steel ratio was effective. Wang [24] experimentally found that the increasing large pore volume fraction is the key reason for the durability failure of RAC under complex environmental factors. Then, a model for predicting the chloride ion migration coefficient and compressive strength of RAC in a complex environment was proposed. Tang et al. [25] investigated the seismic behavior of the RCFST columns and illustrated that the RCFST columns had marginally lower energy dissipation ability, remarkably superior lateral strength, and higher ductility, which indicated that they had good seismic behavior.

However, the compactness of RAC in the steel tube, which has an obvious influence on the confinement between the steel tube and RAC, is difficult to be ensured. Therefore, self-compacting concrete (SCC) is tried in the RCFST as an effective way to solve the problem. Manzi et al. [26] indicated that the mechanical properties of SCC including RA were similar or even superior compared with SCC containing $100 \%$ natural aggregates. Al-Shaar and Göğüș [27] examined the flexural behavior of the self-compacting concrete-filled steel tube (SCCFST) beams. They demonstrated that the filling of the steel tubes with SCC can observably increase the ductility, flexural stiffness, and moment capacity of the steel sections. Mahgub et al. [28] researched the axial compression behaviors of the SCCFST columns and proved that the axial strength of the specimens improved as the SCC compressive strength was enhanced but decreased as the slenderness ratio rose. Tang et al. [29] proved that the SCCFST columns also had a good seismic performance.

In general, plenty of achievements on the RCFST and SCCFST columns have been attained, whereas few investigations have been focused on the recycled self-compacting concrete-filled circular steel tubular (RSCCFCST) columns. Consequently, the failure mode, deformation, and ultimate bearing capacity of the RSCCFCST columns subjected to axial compression are investigated in this study. Nine columns were designed to research the influence of the slenderness ratio and RSCC strength grade on the mechanical properties of the RSCCFCST columns. An analytical model for predicting the ultimate bearing capacity of the
RSCCFCST long columns subjected to axial load is presented on the basis of the tangent modulus theory. In addition, a simplified formula based on the RSCCFCST short columns is proposed by introducing a stability coefficient.

\section{Experimental Program}

2.1. Design and Preparation of the Specimen. Nine RSCCFCST columns were prepared and examined in this experiment, including three short columns as reference groups and six long columns. The thickness and outer diameter of the steel tube were $3.63 \mathrm{~mm}$ and $140 \mathrm{~mm}$, respectively. Different lengths (i.e., $500 \mathrm{~mm}, 1000 \mathrm{~mm}$, and $1500 \mathrm{~mm}$ ), RSCC strength grades (i.e., C30, C50, and C60), and slenderness ratios (i.e., 3.57, 7.14, and 10.71) were considered. The detailed factors are listed in Table 1.

Firstly, both ends of the steel tube should be lathed to ensure that they were flat, and the length must be strictly controlled as designed. Then the steel tube was placed on the flat ground, with the bottom sealed with a piece of plastic film to avoid mortar leakage, whereafter the steel tube was filled with the RSCC without vibration. In order to prevent water evaporation during the hardening process, the top surface was sealed with another piece of plastic film. Before the test, the surface of the specimens was polished to ensure that the steel tube and RSCC could work together in the initial loading stage.

\subsection{Material Properties}

2.2.1. Steel Tube. The steel type Q235 was used to make the circular steel tube. According to Chinese standard GB/ T228.1-2010 (2010) [30], the samples shown in Figure 1 were used in the tensile test and the steel tube with $500 \mathrm{~mm}$ in length, $140 \mathrm{~mm}$ in outer diameter, and $3.63 \mathrm{~mm}$ in thickness was used in the compressive test to obtain the mechanical properties of the steel tube. The measured stress-strain curve and the relationship between the circumferential strain $\left(\varepsilon_{\mathrm{sl}}\right)$ and longitudinal strain $\left(\varepsilon_{\mathrm{sa}}\right)$ are shown in Figures 2(b) and 2(d), respectively. As a result, the yield strength of the steel tube was $233.23 \mathrm{MPa}$, the ultimate tensile strength was 295.68 $\mathrm{MPa}$, and Poisson's ratio and Yong's modulus were 0.297 and $2.00 \times 10^{5} \mathrm{MPa}$, respectively.

2.2.2. RSCC. The RSCC used in the specimens consisted of P. O 42.5R Portland cement, fine aggregates (sand and flyash), RA, polycarboxylate superplasticizer, and city tap water. The continuously graded RA with a particle size range of 5-35 mm formed by crushing the waste concrete blocks was adopted. Table 2 summarizes the proportioning of the RSCC with different strength grades. Moreover, the measured mechanical properties of the RSCC are shown in Table 3.

\subsection{Loading Procedure and Experimental Measurement.}

The experiment was conducted on the electron-hydraulic servo pressure machine. To prevent the destruction of the end parts, both ends of the columns were, respectively, 
TABLE 1: Design parameters of the RSCCFCST columns.

\begin{tabular}{|c|c|c|c|c|c|c|c|c|c|}
\hline Specimen ID & $D(\mathrm{~mm})$ & $L(\mathrm{~mm})$ & $L / D$ & C & $t(\mathrm{~mm})$ & $D / t$ & $N_{e}(\mathrm{kN})$ & $\varepsilon_{\text {uae }}$ & $\varepsilon_{\text {ule }}$ \\
\hline RSCS-1 & 140 & 500 & 3.57 & 30 & 3.63 & 38.56 & 1159 & 0.0143 & -0.0083 \\
\hline RSCS-2 & 140 & 500 & 3.57 & 50 & 3.63 & 38.56 & 1312 & 0.0156 & -0.0092 \\
\hline RSCS-3 & 140 & 500 & 3.57 & 60 & 3.63 & 38.56 & 1331 & 0.0168 & -0.0102 \\
\hline RSCS- 4 & 140 & 1000 & 7.14 & 30 & 3.63 & 38.56 & 1122 & 0.0133 & -0.0074 \\
\hline RSCS-5 & 140 & 1000 & 7.14 & 50 & 3.63 & 38.56 & 1246 & 0.0149 & -0.0088 \\
\hline RSCS-6 & 140 & 1000 & 7.14 & 60 & 3.63 & 38.56 & 1272 & 0.0152 & -0.0097 \\
\hline RSCS-7 & 140 & 1500 & 10.71 & 30 & 3.63 & 38.56 & 1095 & 0.0123 & -0.0064 \\
\hline RSCS- 8 & 140 & 1500 & 10.71 & 50 & 3.63 & 38.56 & 1200 & 0.0135 & -0.0079 \\
\hline RSCS-9 & 140 & 1500 & 10.71 & 60 & 3.63 & 38.56 & 1229 & 0.0141 & -0.0085 \\
\hline
\end{tabular}

Note: $D$ and $t$ are the outside diameter and thickness of the steel tube, respectively. $L$ is the length of the column. $C$ is the number of the RSCC strength grades. $N_{\mathrm{e}}$ is the measured bearing capacity of the specimens. $\varepsilon_{\text {uae }}$ and $\varepsilon_{\text {ule }}$ are the measured ultimate longitudinal and circumferential strains of the specimens, respectively.
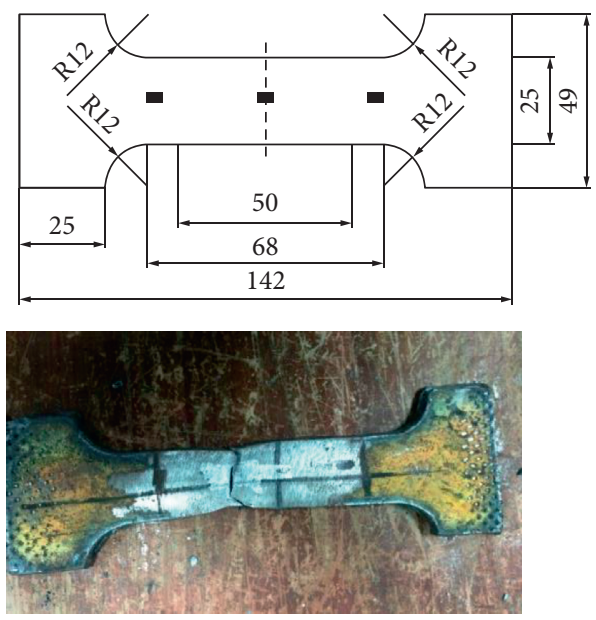

(a)

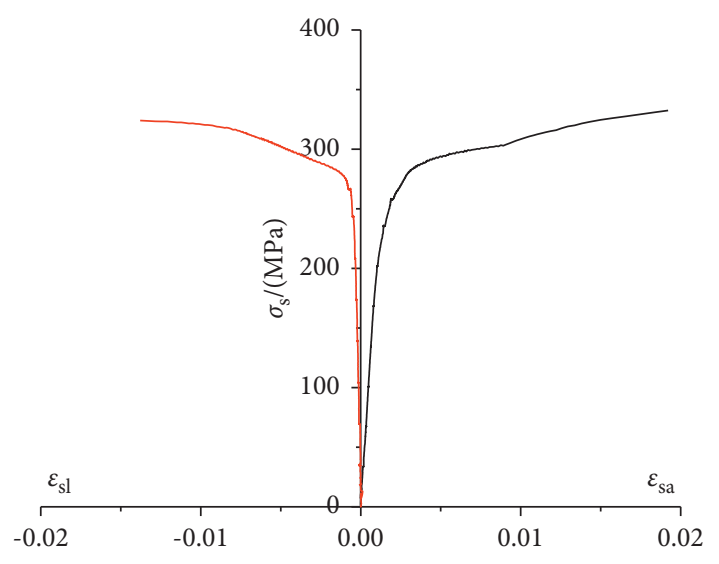

(b)

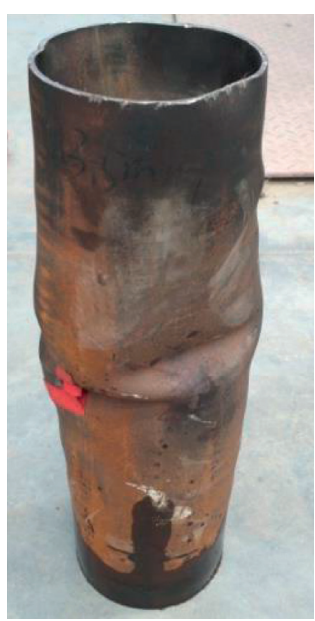

(c)

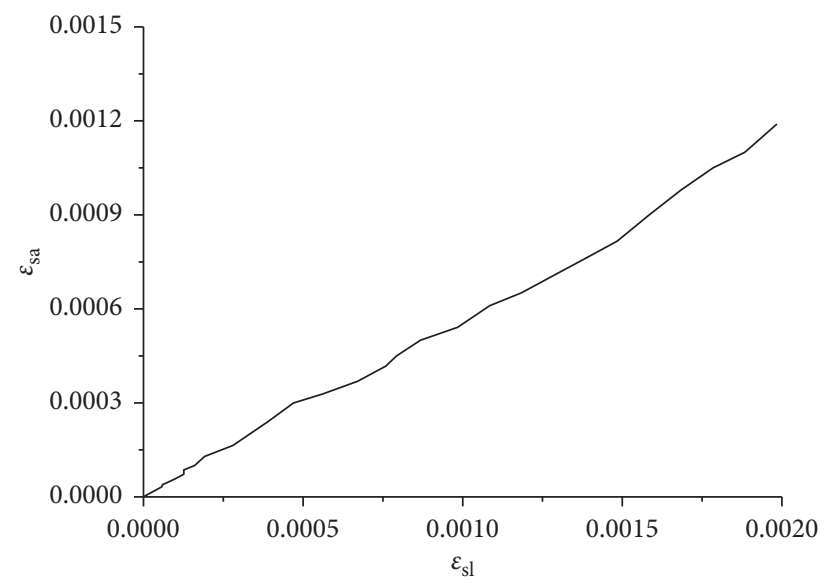

(d)

Figure 1: Test samples and mechanical properties of the steel tube. (a) Tensile sample. (b) Stress-strain curve of the tensile sample. (c) Axial compression steel tube. (d) Relationship between $\varepsilon_{\mathrm{sl}}$ and $\varepsilon_{\mathrm{sa}}$.

sheathed with the steel column caps before applying the load. Figure 3 shows the strain gauges arrangement and the experimental device. Eight strain gauges were installed at the height of $0.25 \mathrm{~L}, 0.5 \mathrm{~L}$, and $0.75 \mathrm{~L}$, respectively (L represents the length of the column), among which four were adopted to measure the lateral strains of the specimens and another four were used to gauge the axial strains. To inspect the axial deformations of the specimens, two linear variable displacement transducers (LVDTs) were arranged at the bottom of the loading plate.

Preloading was performed to ensure that the specimens were subjected to axial load. In the initial phase of the formal 


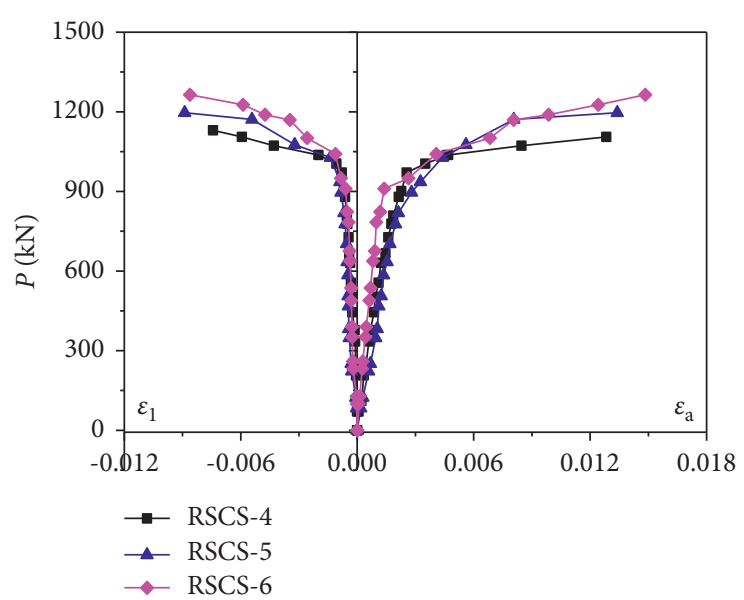

(A)

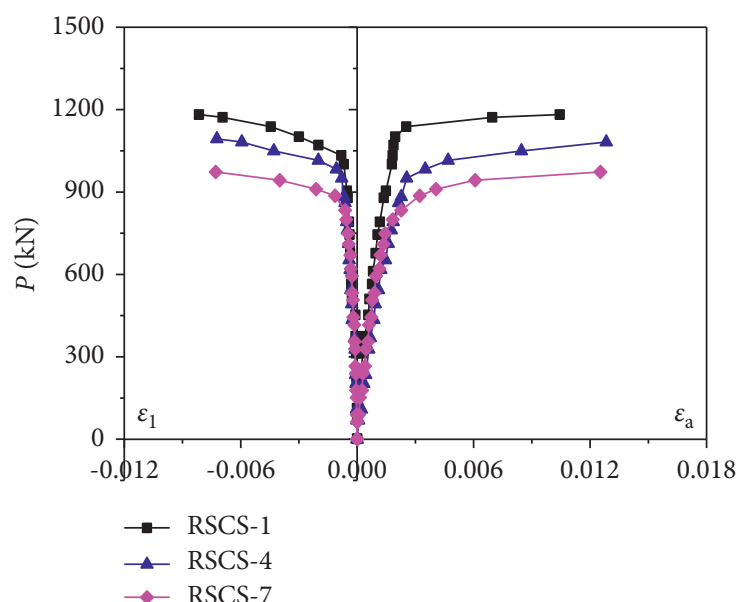

(A)

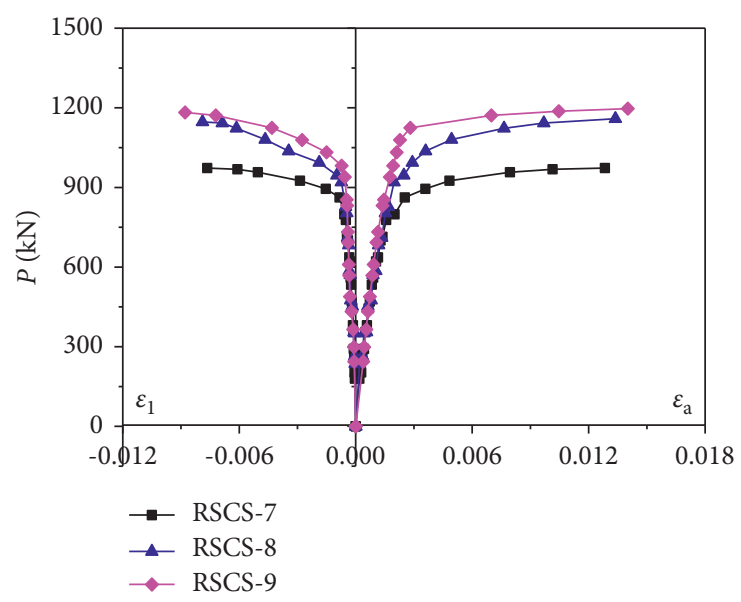

(B)

(a)

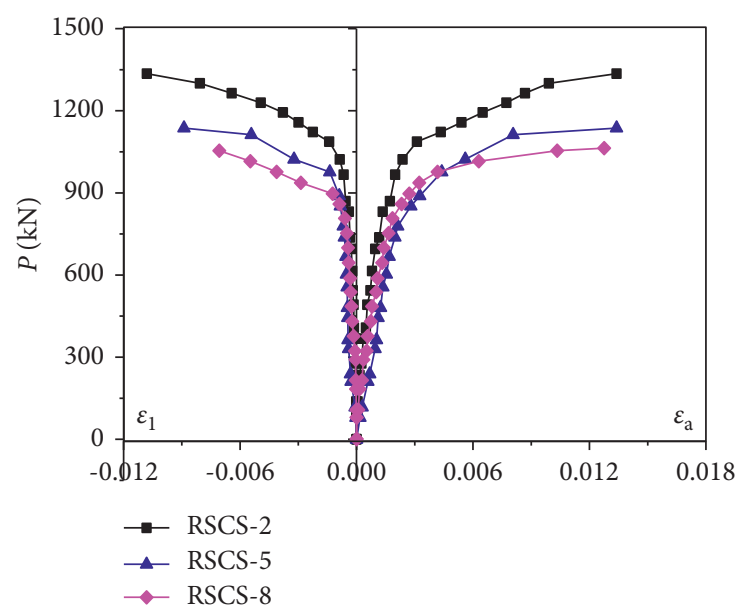

(B)

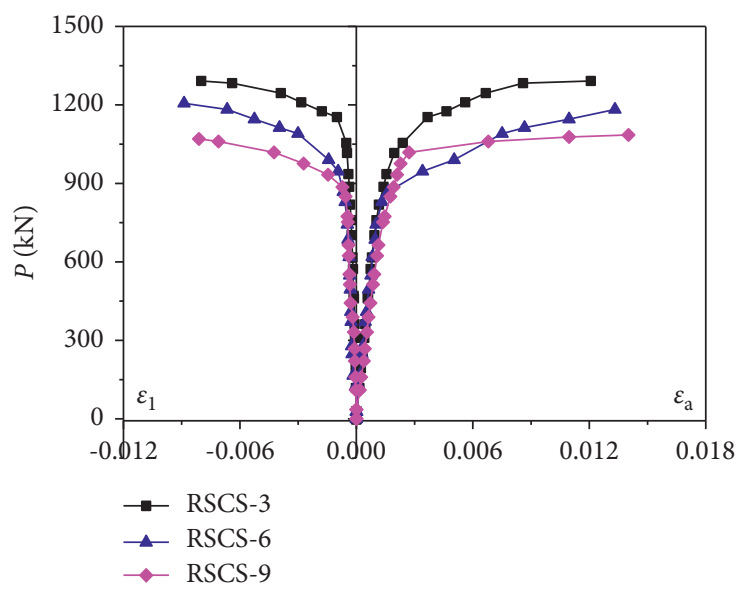

(C)

(b)

FIGURE 2: Effects of the studied parameters on the load-strain relationship. (a) RSCC strength grade. (A) Specimens with L/D 7.14. (B) Specimens with L/D 10.17. (b) Slenderness ratio. (A) Specimens with C30 concrete. (B) Specimens with C50 concrete. (C) Specimens with C60 concrete. 
TABLE 2: Proportioning of RSCC.

\begin{tabular}{lccccccc}
\hline Strength grade & $\begin{array}{c}\text { Water-to-binder } \\
\text { ratio }\end{array}$ & Water $\left(\mathrm{L} / \mathrm{m}^{3}\right)$ & Sand $\left(\mathrm{kg} / \mathrm{m}^{3}\right)$ & $\begin{array}{c}\text { Cement } \\
\left(\mathrm{kg} / \mathrm{m}^{3}\right)\end{array}$ & $\begin{array}{c}\text { Fly-ash } \\
\left(\mathrm{kg} / \mathrm{m}^{3}\right)\end{array}$ & Water reducer $\left(\mathrm{kg} / \mathrm{m}^{3}\right)$ & $\begin{array}{c}\mathrm{RA} \\
\left(\mathrm{kg} / \mathrm{m}^{3}\right)\end{array}$ \\
\hline C30 & 0.46 & 210 & 736 & 305 & 144 & 7.143 \\
C50 & 0.32 & 176 & 798 & 449 & 106 & 798 \\
C60 & 0.28 & 164 & 736 & 477 & 113 & 798 \\
\hline
\end{tabular}

TABLE 3: Mechanical properties of RSCC.

\begin{tabular}{lcccc}
\hline Number & Cube compressive strength $(\mathrm{MPa})$ & Axial compressive strength $(\mathrm{MPa})$ & Poisson's ratio & Young's modulus $\left(10^{4} \mathrm{MPa}\right)$ \\
\hline C30 & 33.0 & 26.3 & 0.152 & 2.31 \\
C50 & 53.4 & 42.8 & 0.168 & 2.73 \\
C60 & 61.8 & 49.5 & 0.165 & 3.02 \\
\hline
\end{tabular}

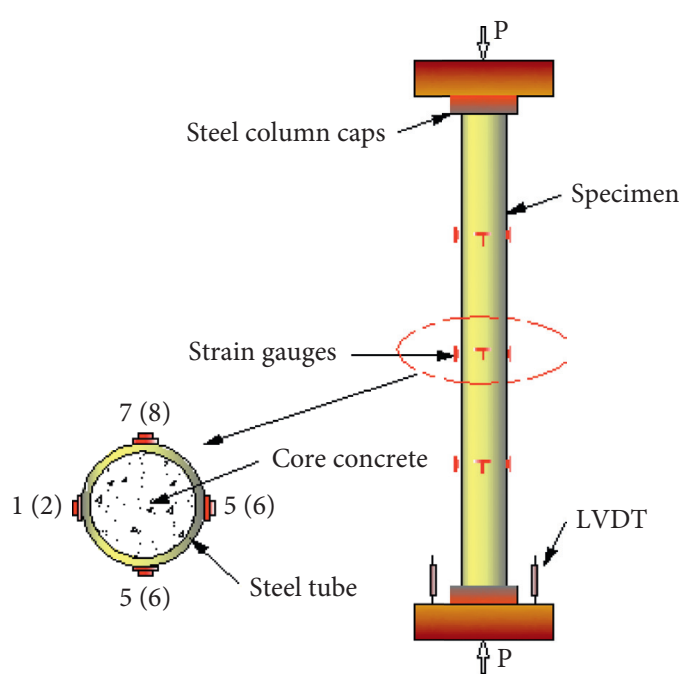

(a)

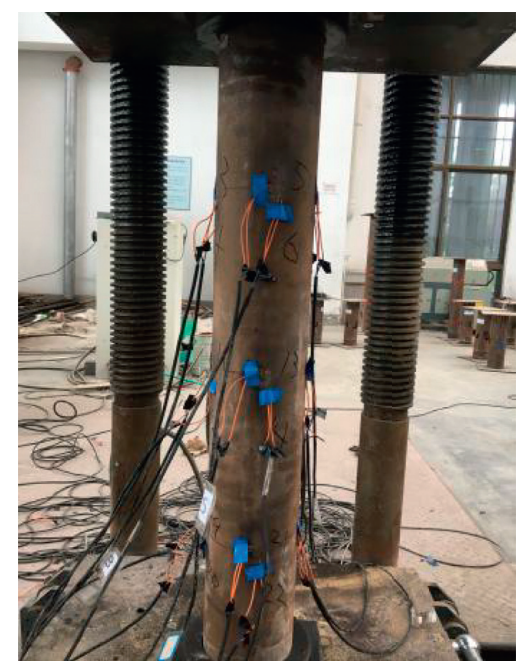

(b)

Figure 3: Strain gauges arrangement and test setup.

loading process, the increment of the load was approximately $10 \%$ of the predicted ultimate strength of the columns. After yielding, the load increment with 1/15 of the predicted ultimate strength of the columns was adopted and each step was kept steady for 2 minutes. When approaching failure, the loading mode became slow and continuous. The failure of the specimens can be determined under the following two conditions. One was that the axial load suddenly dropped sharply to $70 \%$ of the ultimate strength. Another was the compression displacement of the columns came up to $3 \mathrm{~cm}$ if the decrease of the load-displacement curve was unobvious.

\section{Test Results}

3.1. Failure Modes. The failure modes of RSCCFCST specimens are presented in Figure 4. Three stages were approximately divided into the loading and failure process. The first stage, named the elasticity phase, lasted longer as the RSCC strength grade increased and shorter as the slenderness ratio grew. No apparent deformation and deflection were observed in this stage. The vertical displacement and longitudinal and axial strains of the RSCCFCST long columns increased linearly as load increased, and the longitudinal strains of the specimens were basically the same at each direction.

The second stage named elastoplasticity appeared when the strains and vertical displacement deviated from linear growth and the growth rate was accelerated, when no visible deformation was found. The short columns yielded and a slight sound of crushed concrete could be heard when loaded to $80 \%$ of the ultimate strength. However, for the long columns, the development of the longitudinal strains became slow at the tension side and fast at the compression side when loaded to $70 \%$ of the ultimate strength. The increase of the vertical displacement was also obviously accelerated and the deflection was observed in the midspan of the columns. When loaded to about $85 \%$ of the ultimate strength, the midspan deflection was significant, and the growth rate of the strains decreased as the RSCC strength grade improved but increased as the slenderness ratio increased.

Finally, the drum-like bending in the middle of specimens dominated the buckling failure of RSCCFCST short columns, while the development of the deflection was accelerated 


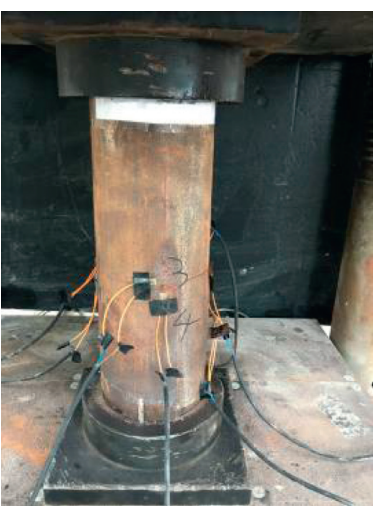

(a)

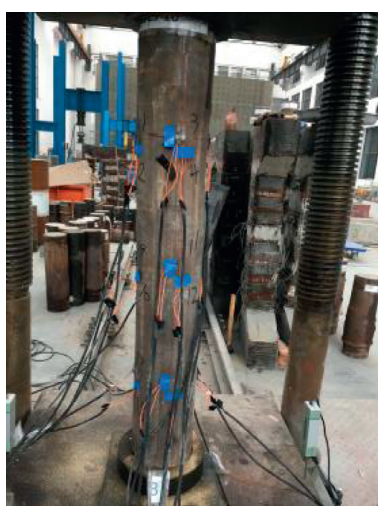

(d)

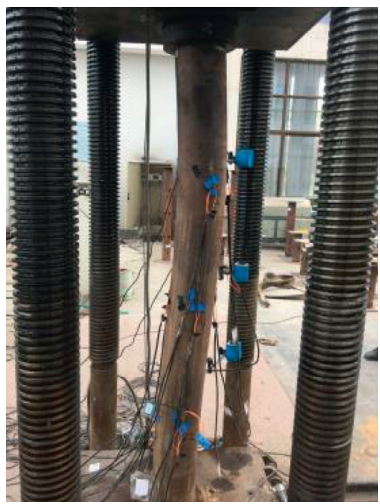

(g)

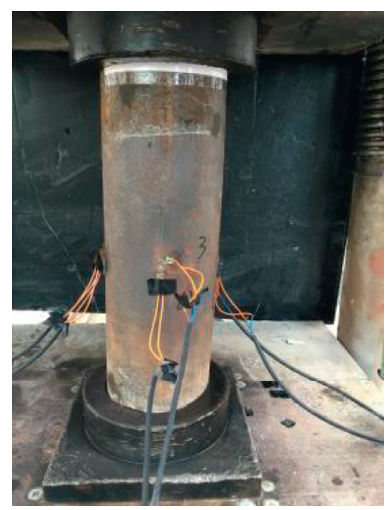

(b)

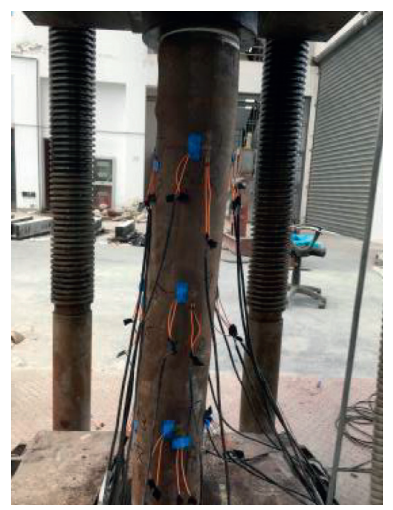

(e)

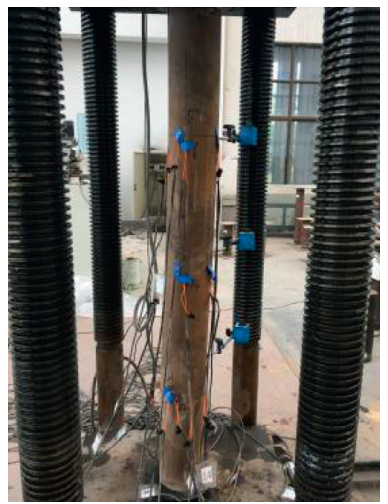

(h)

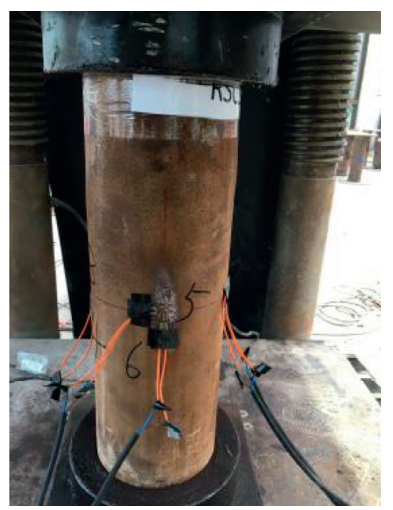

(c)

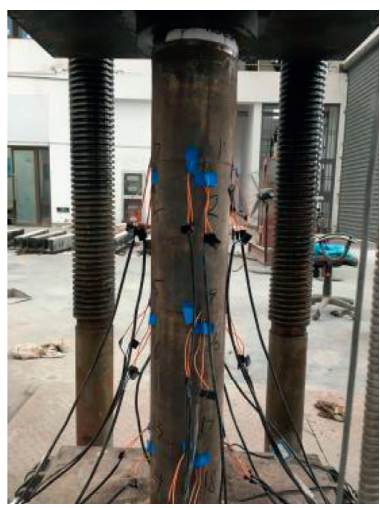

(f)

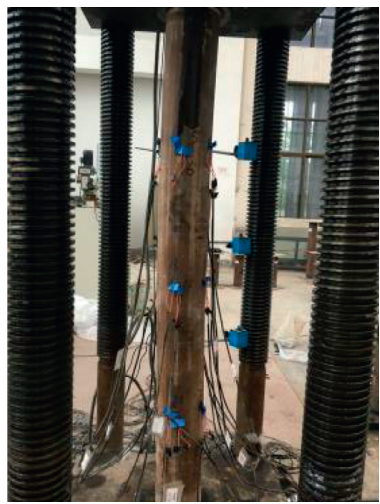

(i)

FIgURE 4: Failure modes of the RSCCFST columns under axial compression. (a) RSCS-1. (b) RSCS-2. (c) RSCS-3. (d) RSCS-4. (e) RSCS-5. (f) RSCS-6. (g) RSCS-7. (h) RSCS-8. (i) RSCS-9.

evidently, and the overall bending instability failure occurred in the long columns. Compared with the short columns, the ultimate strength of long columns decreased significantly and obvious flexural deformation can be observed. The stiffness degeneration is accelerated and the final deflection is more evident as the slenderness ratio rose or the RSCC strength grade is decreased.

3.2. Ultimate Bearing Capacity. The influence of two parameters as the slenderness ratio and RSCC strength grade on the ultimate bearing capacity of the specimens was considered in this paper as discussed in the following.
Figure 5(a) depicts that the ultimate bearing capacity of the specimens improved gradually as the RSCC strength grade increased. For example, compared with the specimen RSCS-4 with the RSCC strength grade C30, the ultimate strength of the specimen RSCS-6 with the RSCC strength grade C60 was enhanced by $13.37 \%$. The main reason was that, as the RSCC strength grade rose, the water-to-cement ratio decreased and the content of the cementing material increased. As a result, the porosity of hardened concrete was reduced. In addition, the bonding force between the cementing material and RA was enhanced. So the compressive strength of the core RSCC increased, and the ultimate bearing capacity improved. 


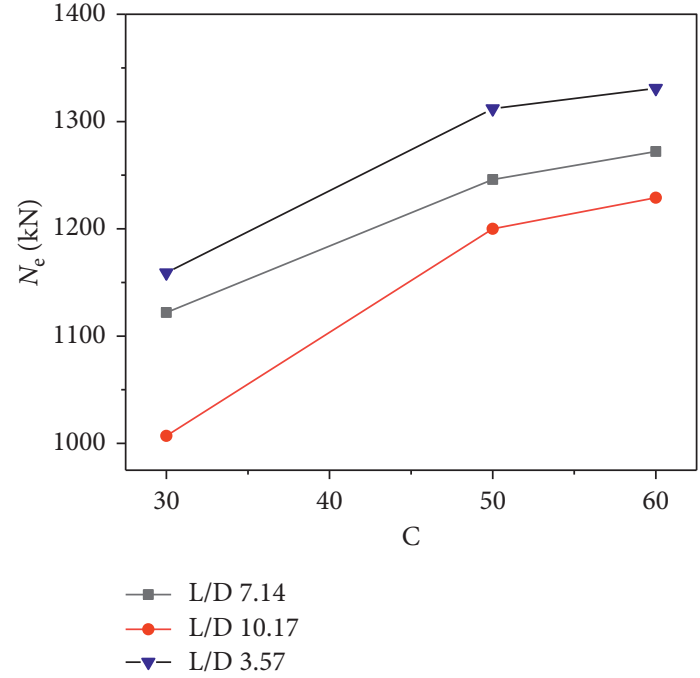

(a)

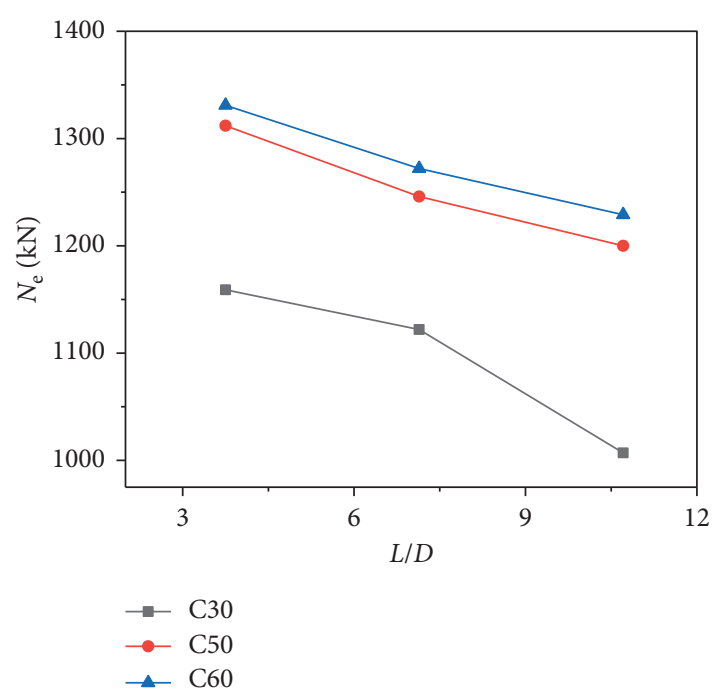

(b)

FIgURE 5: Effects of the studied parameters on the ultimate bearing capacity. (a) RSCC strength grade. (b) Slenderness ratio.

Figure 5(b) indicates the effect of the slenderness ratio on the ultimate bearing capacity of the specimens subjected to axial compression. In general, the increase in the slenderness ratio reduced the ultimate bearing capacity of the specimens gradually. Taking specimen RSCS- 5 and specimen RSCS- 8 for example, the ultimate bearing capacity was reduced by $3.69 \%$ when the slenderness ratio rose from 7.14 to 10.71 . This was due to the fact that the stiffness reduced with the raise of the slenderness ratio, leading to the fact that the deflection development of the columns accelerated and the second-order effect occurred earlier. Accordingly, the bearing capacity of the columns decreased.

3.3. Load-Strain Relationship. The load-strain curves of the RSCCFCST long columns subjected to axial compression are indicated in Figures 2 and 6, in which $P$ is the load and $\varepsilon_{1}$ and $\varepsilon_{a}$ designate the circumferential and longitudinal strains, respectively.

Figure 2(a) demonstrates the influence of the RSCC strength grade on the load-strain relation of the specimens. At the elastic phase, the load-strain curves of the RSCCFCST long columns were linear and basically coincide. After entering the elastoplasticity phase, the strain grew fast, and its development rate increased as the RSCC strength grade decreased until the specimens failed.

As presented in Figure 2(b), the slope of the load-strain curves at the initial loading stage was basically the same. As the loading increased, the load-strain curves of the specimens gently deviated from the linear relationship, the strain growth speed of the specimens rose, and the specimens entered the elastic-plastic stage. The inelastic strain growth rate was accelerated as the slenderness ratio increased.

Figure 6 indicates that the load-strain curves of the specimens at different heights (i.e., $1 / 4 \mathrm{~L}, 1 / 2 \mathrm{~L}$, and $3 / 4 \mathrm{~L}$ ) were almost the same. However, the elastic phase of the loadstrain curve at $1 / 2 \mathrm{~L}$ was relatively longer than that of the other two heights. An obvious inflection point appeared on the load-strain curve when the specimen yielded, and the yield load at the $1 / 2 \mathrm{~L}$ was the highest. After yielding, the growth rate of the strain was faster at $1 / 2 \mathrm{~L}$ than that at the other heights.

3.4. Deformation. The influence of the RSCC strength grade and slenderness ratio on the deformation of the specimens was analyzed as follows.

Figure 7(a) shows the influence of RSCC strength grade on the ultimate longitudinal strain and circumferential strain of the specimens, in which $\varepsilon_{\text {uae }}$ stands for the ultimate longitudinal strain and $\varepsilon_{\text {ule }}$ represents the ultimate circumferential strain. The ultimate circumferential strain and longitudinal strain of the specimens rose gradually as the RSCC strength grade increased. For instance, for the specimens RSCS-7 and RSCS-9, when the RSCC strength grade increased from C30 to C60, the ultimate circumferential strain and longitudinal strain, respectively, increased by $32.81 \%$ and $14.63 \%$. The reason may be that the ultimate bearing capacity of the specimen was enhanced as the RSCC strength grade rose, while the cross-sectional area of the specimen remained unchanged. As a result, the stress increased and the ultimate strain of the specimens increased accordingly.

Figure $7(\mathrm{~b})$ indicates that the ultimate circumferential strain and longitudinal strain of the RSCCFCST long columns decreased gradually as the slenderness ratio increased. For example, the ultimate longitudinal and circumferential strains of the specimen RSCS- 5 with the slenderness ratio of 7.14 , respectively, reduced by $9.40 \%$ and $10.23 \%$ compared to those of the specimen RSCS- 8 with the slenderness ratio of 10.71. This may be because the lateral stiffness and deformation capacity reduced as the slenderness ratio rose.

Figures $8(\mathrm{a})-8(\mathrm{~b})$ indicate the ultimate circumferential strain and longitudinal strain at different heights of the 


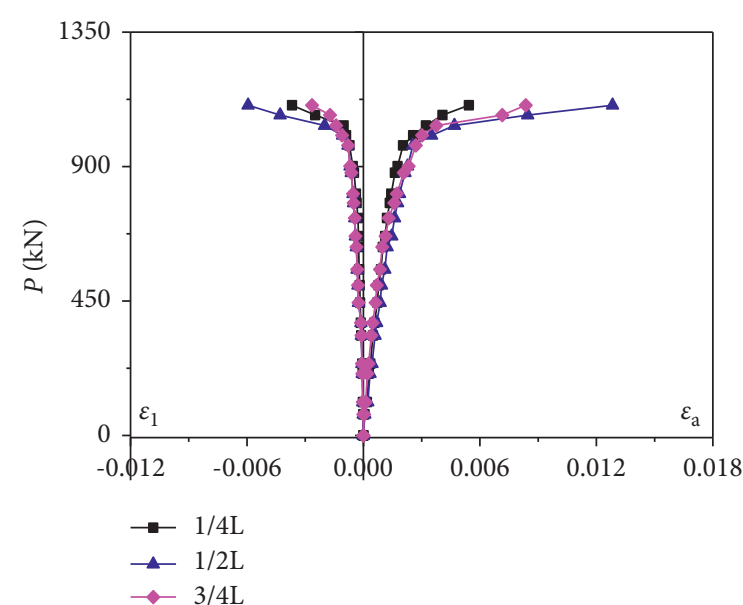

(a)

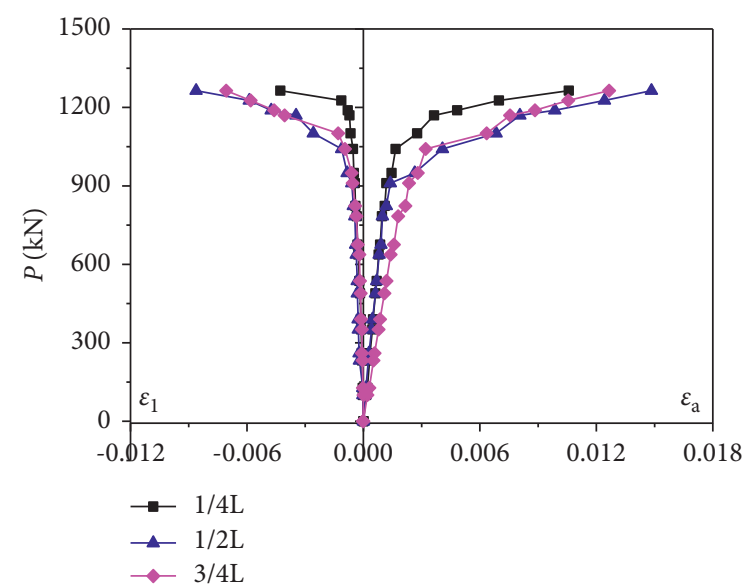

(c)

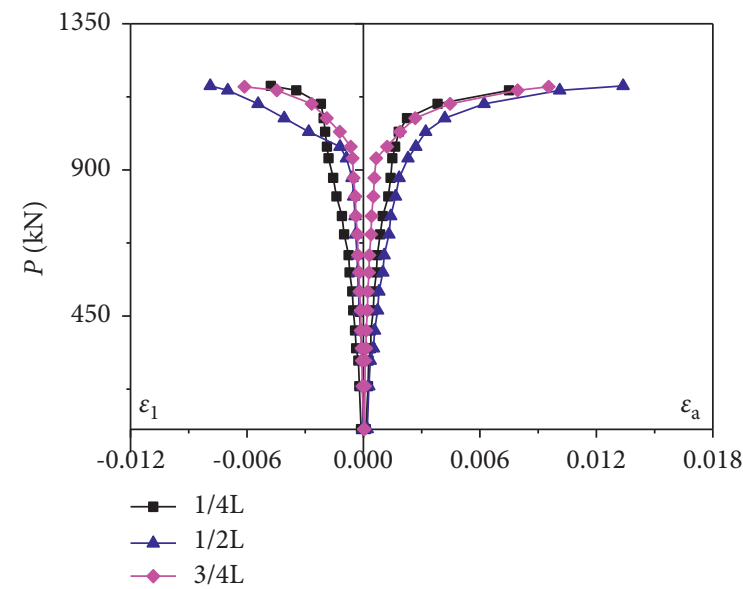

(e)

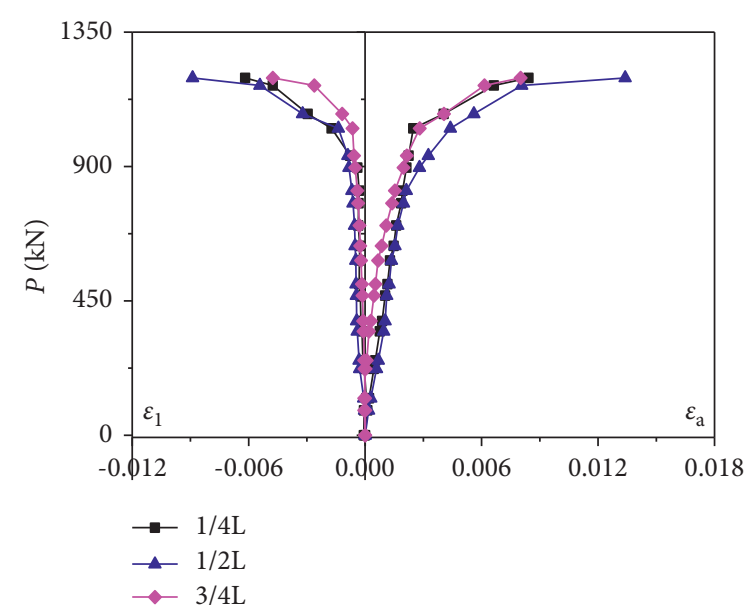

(b)

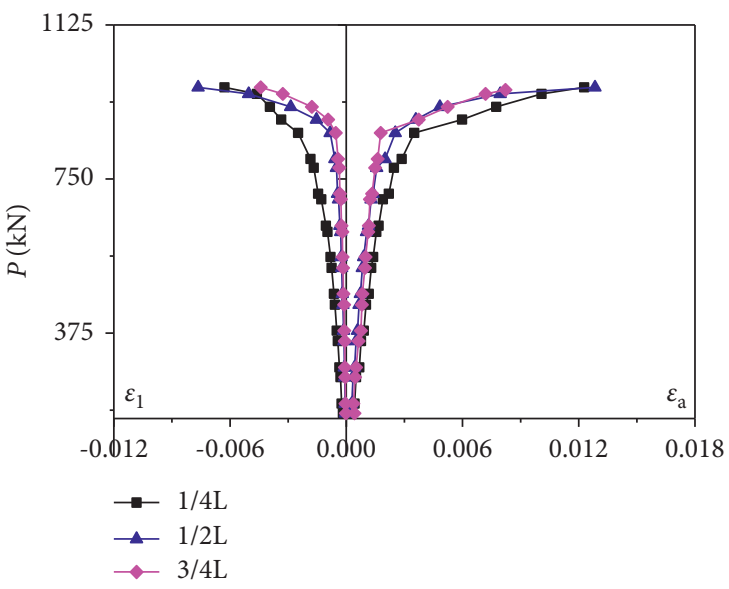

(d)

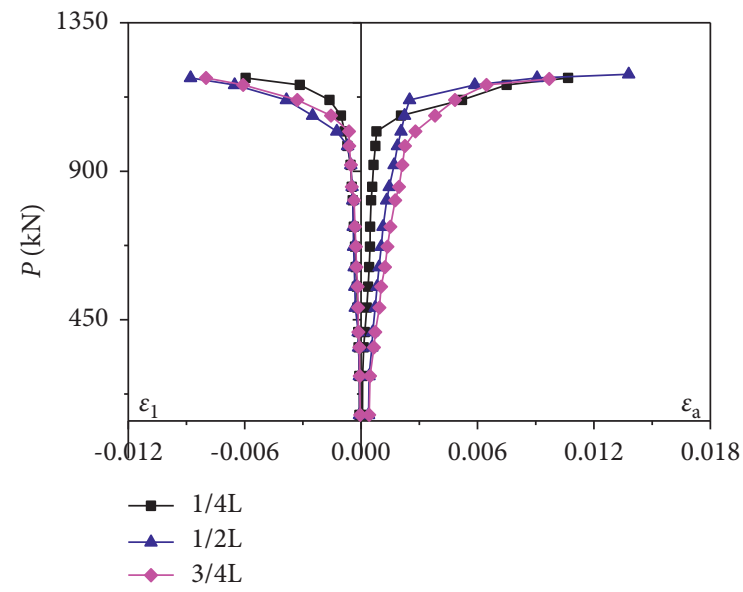

(f)

FIgURE 6: Load-strain curves at different heights of the RSCCFCST long columns. (a) RSCS-4. (b) RSCS-5. (c) RSCS-6. (d) RSCS-7. (e) RSCS-8. (f) RSCS-9.

RSCCFCST long columns. The ultimate strains at $1 / 2 \mathrm{~L}$ were the largest. The strains at $1 / 4 \mathrm{~L}$ and $3 / 4 \mathrm{~L}$ were basically the same. This illustrated that the specimens were in an ideal state of axial compression, which was consistent with the expected results.
3.5. Stiffness Analysis. The influence of two parameters, such as the slenderness ratio and RSCC strength grade, on the stiffness of the specimens was taken into account in Figures 9(a)-9(b), where $N_{e}$ and $K_{e}$ are the axial load and stiffness of the specimens, respectively. Corresponding 


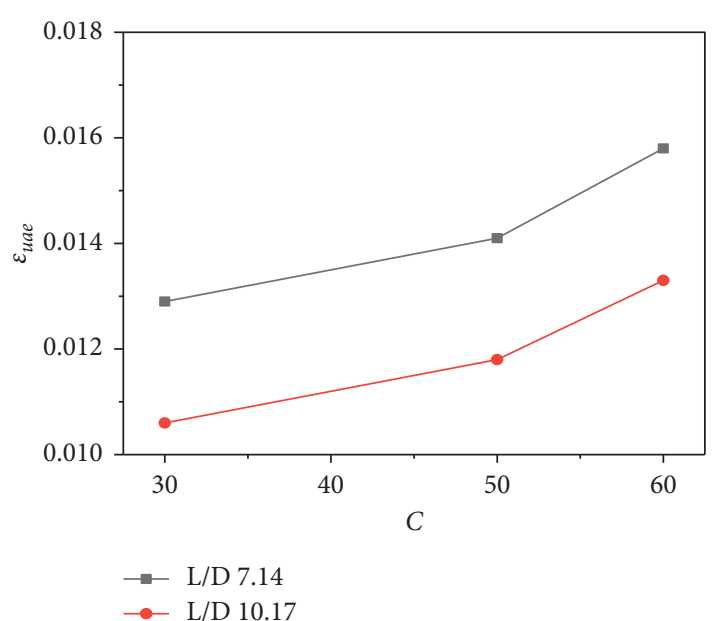

(A)

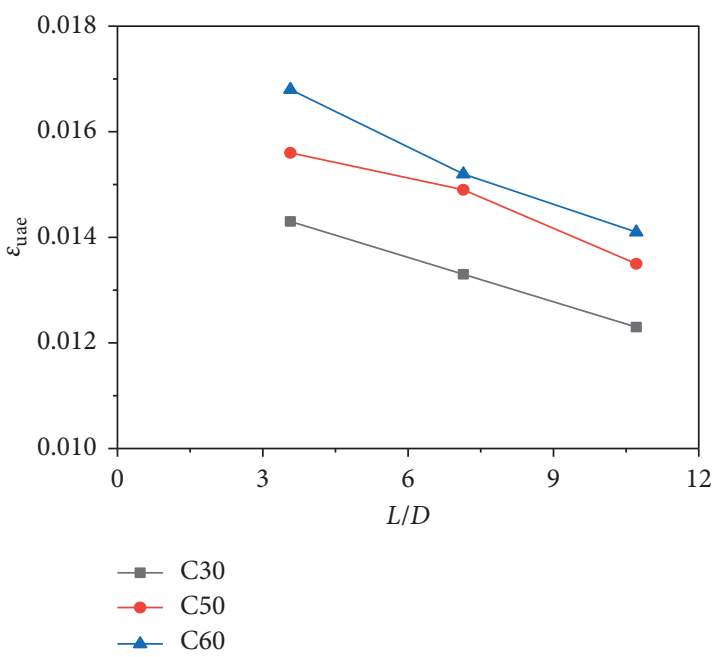

(A)

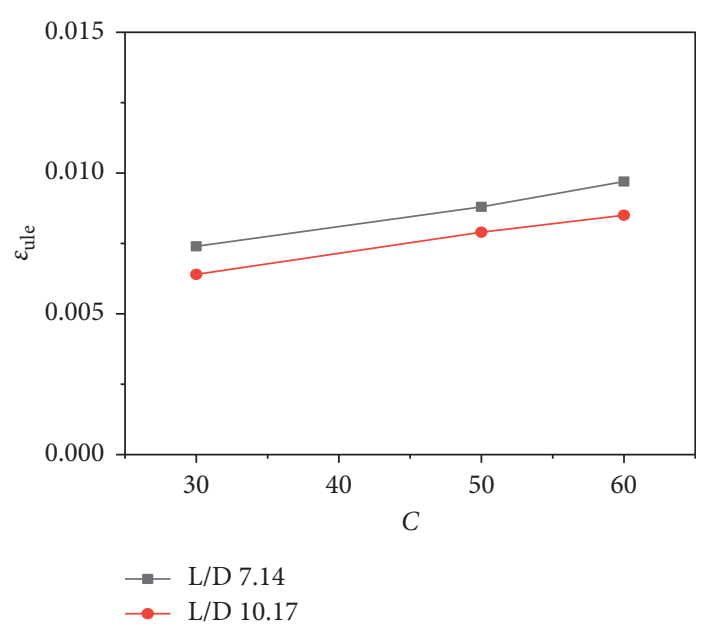

(B)

a)

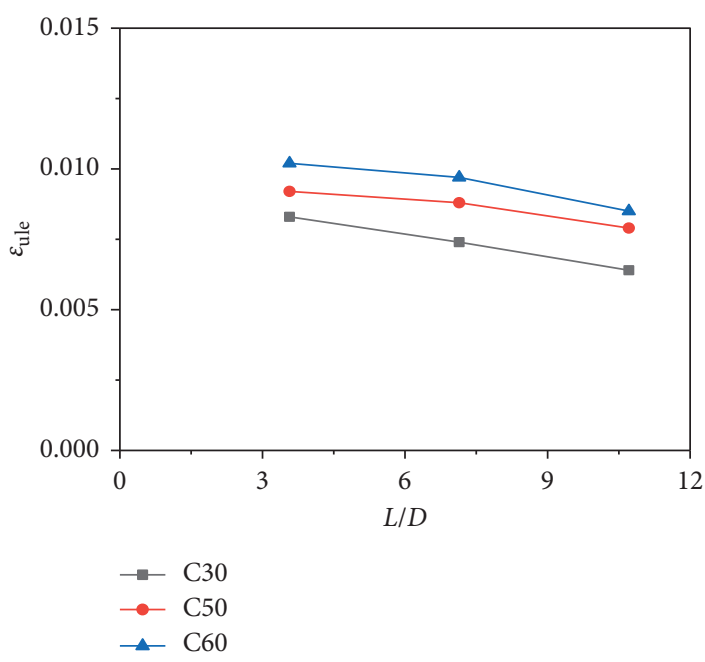

(B)

(b)

FIGURE 7: Effects of the studied parameters on the deformation of the specimens. (a) RSCC strength grade. (A) Ultimate longitudinal strain. (B) Ultimate circumferential strain. (b) Slenderness ratio. (A) Ultimate longitudinal strain. (B) Ultimate circumferential strain.

with the failure process, three stages named elastic, elastoplasticity, and failure were divided. The stiffness curves are basically kept horizontal at the elastic stage. In the elastoplasticity phase, the stiffness of the specimens began to degrade, the curve deviated from the horizontal state. When the ultimate strength was reached, the stiffness remained to degenerate until the specimens failed.

As depicted in Figure 9(a), the horizontal stages of the stiffness curves last longer as the RSCC strength grade increased. The cause may be that the increment of RSCC strength grade improved the compactness and stiffness of RSCC to some degree. When the external steel tubes were kept constant, the overall stiffness of the specimens was improved. The conclusion is slightly different from Figure 9(a), probably due to the fact that (1) few specimens have some defects in the process of fabrication; (2) some data collected at the later loading stage may have some deviations. The stiffness curves showed obvious inflection points when entered into the elastoplasticity stage. When the load approached the ultimate bearing capacity, the increase in RSCC strength grade resulted in the reduction of the stiffness degradation rate.

Figure 9(b) indicates the influence of the slenderness ratio on the stiffness of the specimens. In the elastic stage, the influence of the slenderness ratio on the stiffness of the columns was not significant. Overall, with the increase of the slenderness ratio, the slope of the descending section of the stiffness curves increased, and the degradation rate of the stiffness was accelerated. This was mainly due to the fact that the stiffness of the specimens decreased with the increase in the slenderness ratio. 


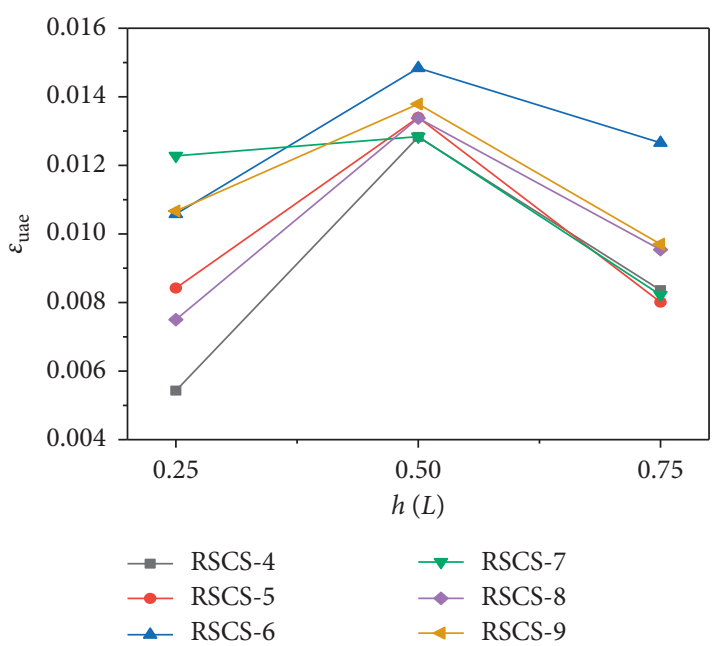

(a)

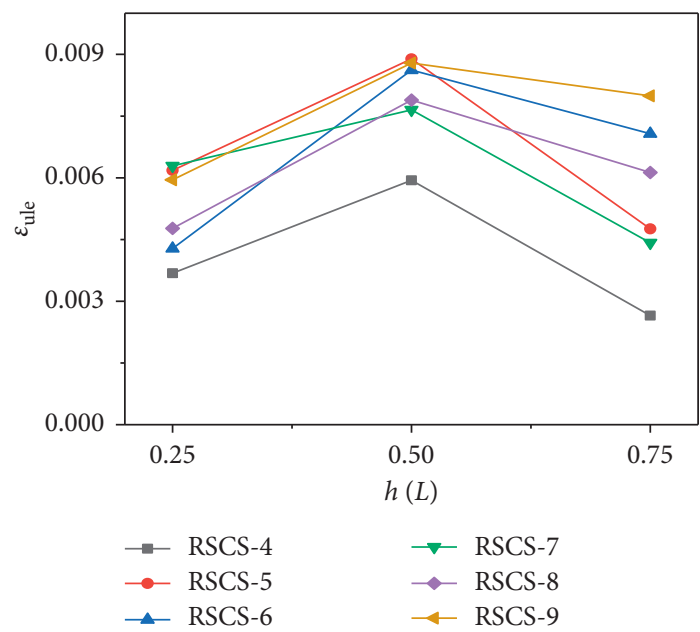

(b)

Figure 8: Ultimate strains at different heights of the specimens. (a) Ultimate longitudinal strain. (b) Ultimate circumferential strain.

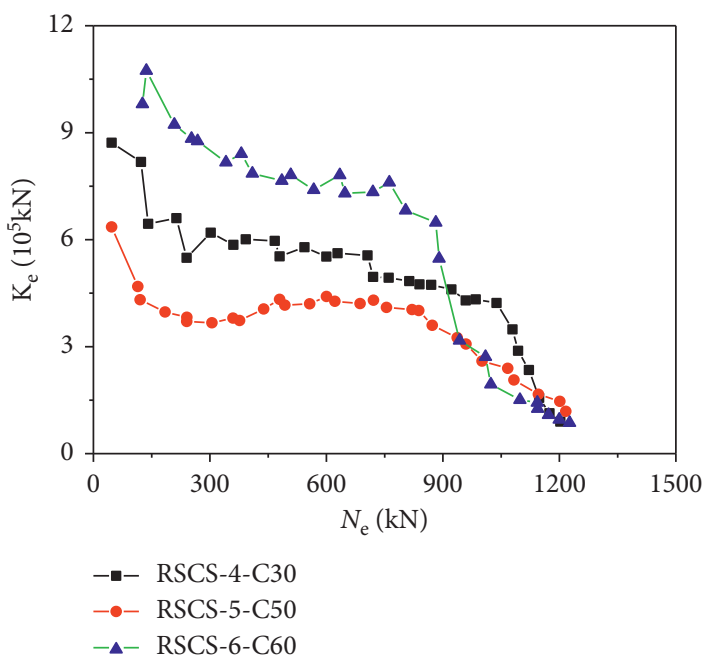

(A)

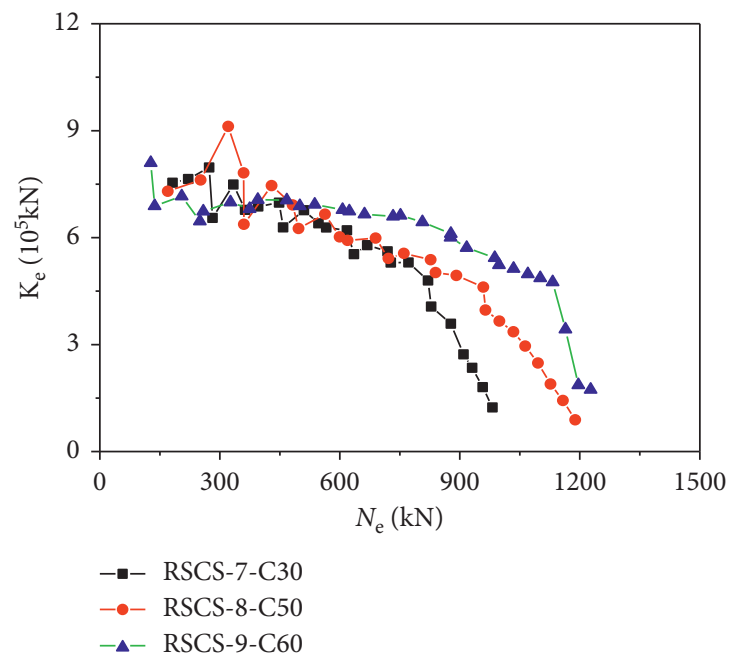

(B)

(a)

Figure 9: Continued. 


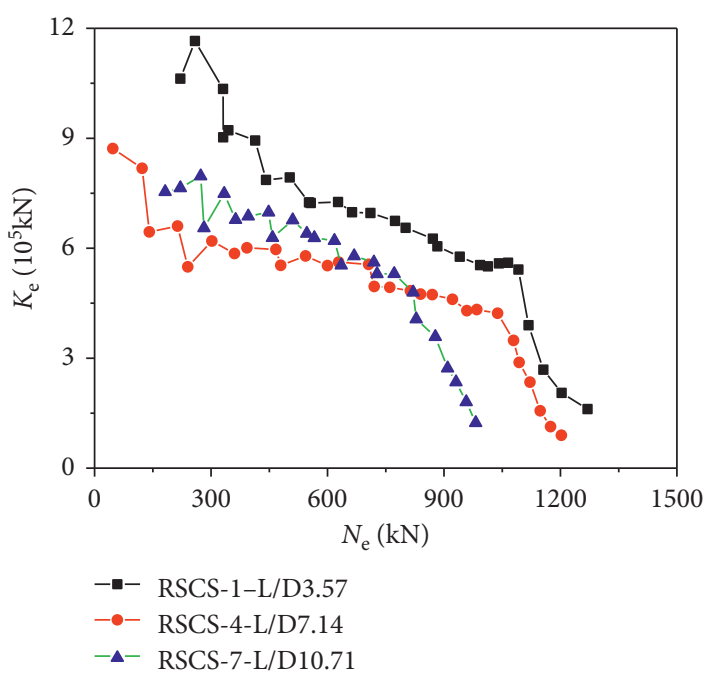

(A)

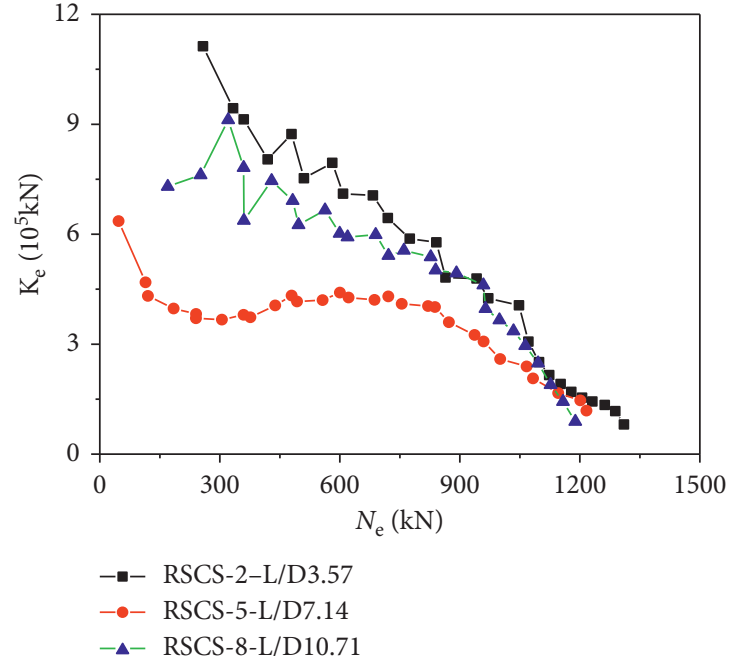

(B)

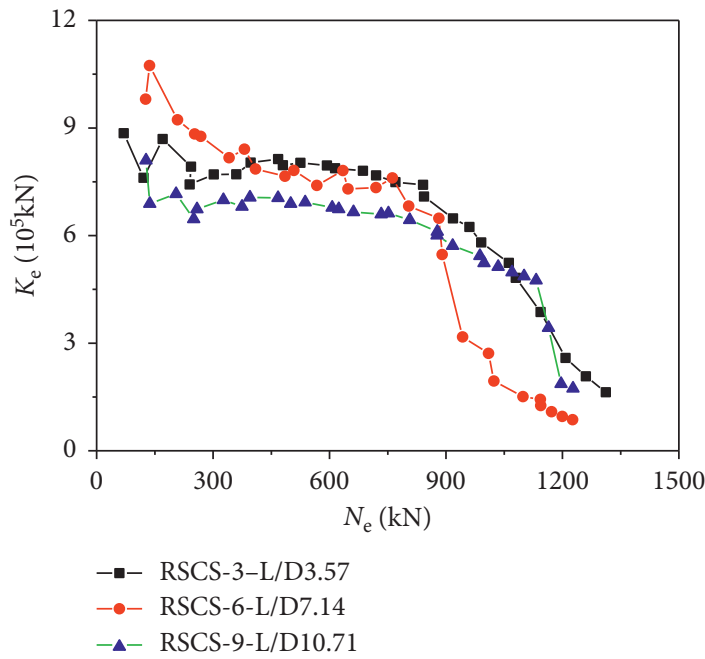

(C)

(b)

Figure 9: Effects of the studied parameters on the stiffness. (a) RSCC strength grade. (A) Specimens with L/D 7.14. (B) Specimens with L/D 10.17. (b) Slenderness ratio. (A) Specimens of C30 concrete. (B) Specimens of C50 concrete. (C) Specimens of C60 concrete.

\section{A New Model for Predicting the Ultimate Bearing Capacity}

4.1. Basic Assumptions. Assumptions were made as follows for the purpose of simplifying the analysis of the RSCCFCST long columns subjected to axial compression:

(1) The RSCCFCST long columns were the ideal straight rods with two hinged ends

(2) The load was ideal axial without any eccentricity

(3) The deflection curve of the specimens was assumed to be a sinusoidal curve in the critical state

4.2. A New Model for Predicting the Ultimate Bearing Capacity. Based on He's [31] analytical model in terms of the combined tangent modulus theory, the calculation model for estimating the ultimate bearing capacity of RSCCFCST long columns subjected to axial load using the modified Euler formula is shown in equation (1). The confining effect of the steel tube on the RAC was considered, and the strength enhancement coefficient of RAC was introduced.

$$
N_{\mathrm{al}}=\frac{\pi^{2} E_{t} I}{L^{2}}
$$

where $N_{a}$ is the Euler critical force, $E_{t}$ stands for the combined tangent modulus, $I$ denotes the moment of the inertia of the long column, and $L$ represents the length of the column. The value of $E_{t}$ and $I$ can be obtained from the following equations: 


$$
\begin{aligned}
E_{t} & =\frac{\left(A_{1} f_{y}-B_{1} \sigma_{0}^{\prime}\right) \sigma_{0}^{\prime}}{\left(f_{y}-f_{p}\right) f_{p}} E, \\
I & =\frac{\pi D^{4}}{64}
\end{aligned}
$$

where $D$ designates the diameter of the long column, $E$ denotes the elastic modulus of the long columns, $\sigma_{0}^{\prime}$ stands for critical stress of the specimen, $A_{1}$ and $B_{1}$ designate the factors acquired by regression analysis, respectively, $f_{p}$ represents the combined limit of the proportionality of the axially loaded specimen, and $f_{y}$ is the combined yield strength of the specimen. The strength enhancement coefficient of RAC $\mu$ was introduced here to modify $f_{y}$ considering the influence of the confining effect of steel tube on RAC. $E, \sigma_{0}^{\prime}, A_{1}, B_{1}, f_{p}, f_{y}$, and $\mu$ are determined as follows:

$$
\begin{aligned}
E & =\frac{f_{p}}{\varepsilon_{p}}, \\
\sigma_{0}^{\prime} & =\frac{N_{\mathrm{al}}}{A_{\mathrm{sc}}} \\
A_{1} & =1-\frac{E^{\prime}}{E}\left(\frac{f_{p}}{f_{y}}\right)^{2}, \\
B_{1} & =1-\frac{E^{\prime}}{E}\left(\frac{f_{p}}{f_{y}}\right), \\
f_{p} & =\left(0.192 \frac{f_{\mathrm{sy}}}{235}+0.488\right) f_{y}, \\
f_{y} & =\left(1.212+C_{1} \theta+D_{1} \theta^{2}\right) \mu f_{\mathrm{co}}, \\
\mu & =\frac{f_{\mathrm{ck}}}{f_{\mathrm{co}}}
\end{aligned}
$$

where $\varepsilon_{p}$ stands for the combined proportional limit strain of the RSCCFCST long column, $A_{\mathrm{sc}}$ represents the crosssectional area of the specimen, $E^{\prime}$ denotes the strainhardening modulus of RAC, $C_{1}$ and $D_{1}$ stand for the factors acquired by regression analysis, respectively, $\theta$ is the confining effect coefficient, $f_{\text {sy }}$ designates the yield strength of steel tube, and $f_{c o}$ denotes the uniaxial compressive strength of RAC and $f_{\mathrm{co}}=0.67 f_{\mathrm{cu}} \cdot f_{\mathrm{cu}}$ and $f_{\mathrm{ck}}$ are the cube and axial compressive strength of RAC, respectively.

$$
\begin{aligned}
& \varepsilon_{p}=\frac{0.67 f_{\text {sy }}}{E_{s}}, \\
& E^{\prime}= \begin{cases}5000 \alpha+550, & \theta \geq 0.96, \\
400 \theta-150, & \theta<0.96,\end{cases}
\end{aligned}
$$

$$
\begin{aligned}
\theta & =\frac{A_{s} f_{\text {sy }}}{A_{c} f_{\text {co }}}, \\
C_{1} & =0.1689 \frac{f_{\text {sy }}}{235}+0.955, \\
D_{1} & =-0.1017 \frac{\mu f_{\text {co }}}{20}+0.0297,
\end{aligned}
$$

where $E_{s}$ stands for Yong's modulus of the steel tube and $\alpha$ is the steel ratio and $\alpha=\left(A_{s} / A_{c}\right) . A_{c}$ and $A_{s}$ designate the cross-sectional areas of RAC and steel tube, respectively.

When equations (2)-(15) were considered, (1) was changed into (16) as follows:

$$
N_{\mathrm{al}}=\frac{A_{1} f_{y} A_{\mathrm{sc}}}{B_{1}}-\frac{L_{c}^{2}\left(f_{y}-f_{p}\right) A_{\mathrm{sc}}^{2} f_{p}}{\pi^{2} \mathrm{EIB}_{1}} .
$$

\subsection{Simplified Formula for Predicting the Ultimate Bearing} Capacity. The experimental results and discussion showed that the ultimate bearing capacity of the specimens reduced gradually as the slenderness ratio rose. Comparing the long columns to short columns, it can be found that the ultimate bearing capacity of the long columns can be simplified to estimate based on the ultimate bearing capacity of the short columns by introducing a stability coefficient named $\varphi_{1}$. Regression analysis was conducted on mass data from this experiment and the others [22,32-36] to obtain the relationship between $\varphi_{1}$ and $L / D$ as shown in Figure 10 and equation (20).

$$
\begin{aligned}
N_{1}^{\prime} & =\varphi_{1} N \\
N & =A_{c} f_{c(\gamma)}(2 \theta+1), \\
\theta & =\frac{A_{s} f_{\mathrm{sy}}}{A_{c} f_{c(\gamma)}}, \\
\varphi_{1} & =-0.0013\left(\frac{L}{D}\right)^{2}+0.0029\left(\frac{L}{D}\right)+0.992, \\
f_{c(\gamma)} & =(1-0.097 \gamma) f_{\mathrm{ck}},
\end{aligned}
$$

where $N_{1}^{\prime}$ and $N$ designate the ultimate bearing capacity of the long columns and short columns, respectively, $\theta$ represents the confining effect coefficient considering the effect of RA, $\gamma$ stands for the replacement ratio of RA, and $f_{c(\gamma)}$ denotes the axial compressive strength of the RA prism.

4.4. Evaluation of the Accuracy for Different Models. To estimate the accuracy of different models, the experimental results in this paper were analyzed. Different 


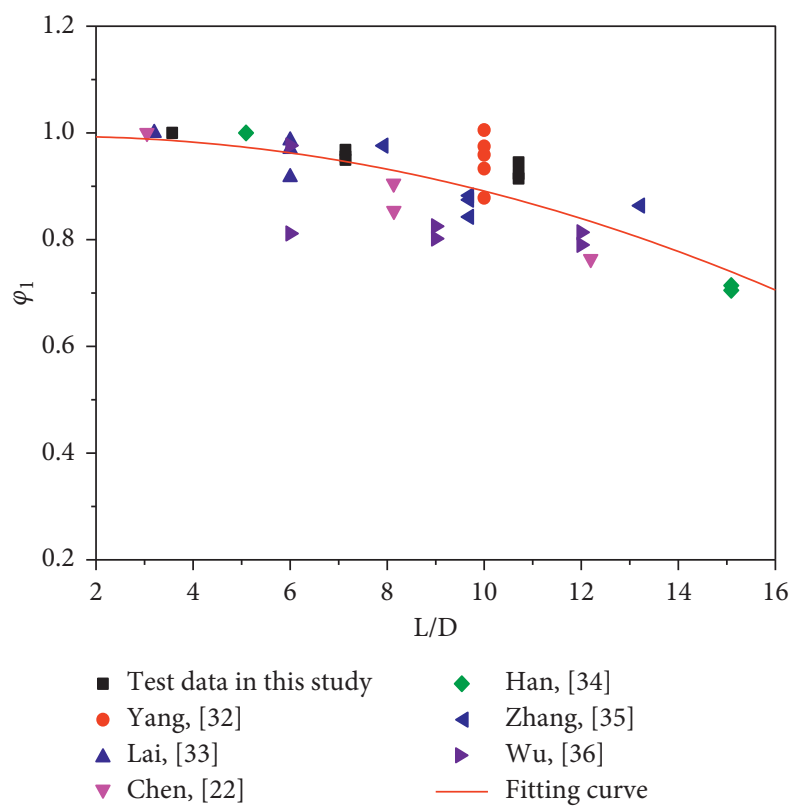

FIGURE 10: Relationship between $\varphi_{1}$ and $L / D$.

TABLE 4: Comparison between the theoretically predicted values and experimental results.

\begin{tabular}{|c|c|c|c|c|c|c|c|c|c|}
\hline \multicolumn{2}{|c|}{ Specimen number } & RSCS-4 & RSCS-5 & RSCS-6 & RSCS-7 & RSCS-8 & RSCS-9 & Average value & Mean variance \\
\hline Test data & $N_{\mathrm{e}}(k N)$ & 1122 & 1246 & 1272 & 1095 & 1200 & 1229 & - & \\
\hline \multirow{2}{*}{ Formula } & $N_{1}(k N)$ & 954 & 1247 & 1368 & 928 & 1214 & 1332 & - & \\
\hline & $N_{1} / N_{\mathrm{e}}$ & 0.850 & 1.001 & 1.075 & 0.848 & 1.012 & 1.083 & 0.978 & 0.096 \\
\hline \multirow{2}{*}{ Simplified model } & $N^{\prime}(k N)$ & 1030 & 1246 & 1334 & 952 & 1151 & 1232 & - & \\
\hline & $N^{\prime} / N_{\mathrm{e}}$ & 0.918 & 1.000 & 1.049 & 0.869 & 0.959 & 1.002 & 0.966 & 0.059 \\
\hline \multirow{2}{*}{ GB50936-2014 } & $N_{\mathrm{GB}}(k N)$ & 911 & 1185 & 1292 & 832 & 1083 & 1179 & - & \\
\hline & $N_{\mathrm{GB}} / N_{e}$ & 0.812 & 0.951 & 1.016 & 0.760 & 0.902 & 0.960 & 0.900 & 0.088 \\
\hline \multirow{2}{*}{ AISC360-16-2016 } & $N_{\text {AISC }}(k N)$ & 522 & 624 & 692 & 516 & 616 & 683 & - & \\
\hline & $N_{A I S C} / N_{e}$ & 0.465 & 0.501 & 0.544 & 0.471 & 0.513 & 0.556 & 0.508 & 0.037 \\
\hline \multirow{2}{*}{ AIJ-SRC-2001 } & $N_{\mathrm{AIJ}}(k N)$ & 808 & 1095 & 1215 & 774 & 1052 & 1166 & - & \\
\hline & $N_{\mathrm{AIJ}} / N_{e}$ & 0.721 & 0.879 & 0.955 & 0.707 & 0.877 & 0.949 & 0.848 & 0.100 \\
\hline \multirow{2}{*}{ EC4-2004 } & $N_{\mathrm{EC}}(k N)$ & 626 & 784 & 850 & 577 & 734 & 798 & - & \\
\hline & $N_{\mathrm{EC}} / N_{e}$ & 0.558 & 0.629 & 0.669 & 0.527 & 0.612 & 0.650 & 0.607 & 0.050 \\
\hline
\end{tabular}

specifications for designing the CFST columns, such as Chinese code GB50936-2014 [37], American standard AISC360-16-2016 [38], Japanese code AIJ-SRC-2001 [39], and European standard EC4-2004 [40], were also compared as depicted in Table 4 . It can be found that the average ratios of the predicted values by AISC360-162016 and EC4-2004 to the test data were 0.508 and 0.607 , and the standard deviations were 0.037 and 0.050 , respectively, which indicated that American and European standards were conservative on estimating the ultimate bearing capacity. Chinese code and Japanese code were comparatively accurate. The average ratios of the predicted values by GB50936-2014 and AIJ-SRC-2001 to the test data were 0.900 and 0.848 , and the standard deviations were 0.088 and 0.100 , respectively. However, the discrepancy between the presented model as equation (16) and experimental results was merely $2.2 \%$, while the simplified model as equation (17) made $3.4 \%$ discrepancy to the experimental data, and the standard deviations were 0.096 and 0.059 , respectively. Correspondingly, the proposed models in this study were superior for evaluating the ultimate bearing capacity than the other existing specifications mentioned.

\section{Conclusions}

A sequence of experiments on the static behaviors of the RSCCFCST columns under axial compression was carried out, and the conclusions were summarized as follows:

(1) The drum-like bending in the middle of the specimens dominated the failure of RSCCFCST short columns. In contrast, the lateral deflection dominated the buckling failure of the RSCCFST long columns subjected to axial load, just as normal CFST long columns.

(2) The ultimate bearing capacity of the RSCCFCST long columns increased gradually as the RSCC strength grade increased but decreased as the slenderness ratio rose. 
(3) As the RSCC strength grade increased or slenderness ratio reduced, the stiffness, ultimate circumferential strain, and longitudinal strain of the columns were aggrandized gradually.

(4) Based on the combined tangent modulus theory, an estimation model was proposed to predict the ultimate bearing capacity of the RSCCFCST long columns, whereafter, by introducing a stability coefficient, a simplified model was suggested according to the ultimate bearing capacity of the RSCCFCST short columns.

(5) Comparisons of the ultimate bearing capacity of the RSCCFCST long columns under axial compression estimated by various specifications and the proposed models in this study indicated that American and European standards were a little conservative and Chinese code and Japanese code were comparatively accurate, while the proposed models in this study were the most accurate.

\section{Data Availability}

The data used to support the findings of this study are included within the article.

\section{Conflicts of Interest}

The authors declare that they have no conflicts of interest.

\section{Acknowledgments}

This work was supported by the Opening Funds of State Key Laboratory of Building Safety and Built Environment and National Engineering Research Center of Building Technology (no. BSBE2020-4), the National Natural Science Foundation of China (nos. 51578001, 51878002, and 52078001), the Outstanding Youth Fund of Anhui Province (no. 2008085J29), the Natural Science Research Project of Anhui Universities (nos. KJ2020A0234 and KJ2020A0261), the Key Research and Development Plan of Anhui Province (no. 1704a0802131), and the University Synergy Innovation Program of Anhui Province (no. GXXT-2019-005).

\section{References}

[1] A. Akhtar and A. K. Sarmah, "Construction and demolition waste generation and properties of recycled aggregate concrete: a global perspective," Journal of Cleaner Production, vol. 186, pp. 262-281, 2018.

[2] J. Xiao, Z. Ma, T. Sui, A. Akbarnezhad, and Z. Duan, "Mechanical properties of concrete mixed with recycled powder produced from construction and demolition waste," Journal of Cleaner Production, vol. 188, pp. 720-731, 2018.

[3] F. Kazemian, H. Rooholamini, and A. Hassani, "Mechanical and fracture properties of concrete containing treated and untreated recycled concrete aggregates," Construction and Building Materials, vol. 209, pp. 690-700, 2019.

[4] K. Hu, Y. Chen, F. Naz, C. Zeng, and S. Cao, "Separation studies of concrete and brick from construction and demolition waste," Waste Management, vol. 85, pp. 396-404, 2019.
[5] S. Lockrey, K. Verghese, E. Crossin, and H. Nguyen, "Concrete recycling life cycle flows and performance from construction and demolition waste in Hanoi," Journal of Cleaner Production, vol. 179, pp. 593-604, 2018.

[6] K. P. Verian, W. Ashraf, and Y. Cao, "Properties of recycled concrete aggregate and their influence in new concrete production," Resources, Conservation and Recycling, vol. 133, pp. 30-49, 2018.

[7] C.-S. Poon and D. Chan, "The use of recycled aggregate in concrete in Hong Kong," Resources, Conservation and Recycling, vol. 50, no. 3, pp. 293-305, 2007.

[8] J. Thomas, N. N. Thaickavil, and P. M. Wilson, "Strength and durability of concrete containing recycled concrete aggregates," Journal of Building Engineering, vol. 19, pp. 349-365, 2018.

[9] G. Dimitriou, P. Savva, and M. F. Petrou, "Enhancing mechanical and durability properties of recycled aggregate concrete," Construction and Building Materials, vol. 158, pp. 228-235, 2018.

[10] S. Laserna and J. Montero, "Influence of natural aggregates typology on recycled concrete strength properties," Construction and Building Materials, vol. 115, pp. 78-86, 2016.

[11] K. B. Ngoc, S. Tomoaki, and T. Hiroshi, "Mechanical properties of concrete containing $100 \%$ treated coarse recycled concrete aggregate," Construction and Building Materials, vol. 163, pp. 496-507, 2018.

[12] V. W. Y. Tam, C. M. Tam, and K. N. Le, "Removal of cement mortar remains from recycled aggregate using pre-soaking approaches," Resources, Conservation and Recycling, vol. 50, no. 1, pp. 82-101, 2007.

[13] S.-C. Kou and C.-S. Poon, "Properties of concrete prepared with PVA-impregnated recycled concrete aggregates," Cement and Concrete Composites, vol. 32, no. 8, pp. 649-654, 2010.

[14] M. Limbachiya, M. S. Meddah, and Y. Ouchagour, "Use of recycled concrete aggregate in fly-ash concrete," Construction and Building Materials, vol. 27, no. 1, pp. 439-449, 2012.

[15] Z. Xiong, W. Wei, F. Liu et al., "Bond behaviour of recycled aggregate concrete with basalt fibre-reinforced polymer bars," Composite Structures, vol. 256, Article ID 113078, 2021.

[16] Z. Xiong, W. Wei, S. He, F. Liu, H. Luo, and L. Li, "Dynamic bond behaviour of fibre-wrapped basalt fibre-reinforced polymer bars embedded in sea sand and recycled aggregate concrete under high-strain rate pull-out tests," Construction and Building Materials, vol. 276, Article ID 122195, 2021.

[17] D. H. Nguyen, W.-K. Hong, H.-J. Ko, and S.-K. Kim, "Finite element model for the interface between steel and concrete of CFST (concrete-filled steel tube)," Engineering Structures, vol. 185, pp. 141-158, 2019.

[18] L.-H. Han and Y. F. An, "Performance of concrete-encased CFST stub columns under axial compression," Journal of Constructional Steel Research, vol. 93, no. 1, pp. 62-76, 2014.

[19] J. Cho, J. Moon, H. J. Ko, and H.-E. Lee, "Flexural strength evaluation of concrete-filled steel tube (CFST) composite girder," Journal of Constructional Steel Research, vol. 151, pp. 12-24, 2018.

[20] L. H. Han, W. Li, and R. Bjorhovde, "Developments and advanced applications of concrete-filled steel tubular (CFST) structures: members," Journal of Constructional Steel Research, vol. 100, pp. 211-228, 2014.

[21] M. Dundu, "Compressive strength of circular concrete filled steel tube columns," Thin-Walled Structures, vol. 56, pp. 6270, 2012. 
[22] J. Chen, Y. Y. Wang, C. W. Roeder, and J. Ma, "Behavior of normal-strength recycled aggregate concrete filled steel tubes under combined loading," Engineering Structures, vol. 130, pp. 23-40, 2017.

[23] W. G. Li, Z. Y. Luo, C. Q. Wu, V. W. Y. Tam, W. H. Duan, and S. P. Shah, "Experimental and numerical studies on impact behaviors of recycled aggregate concrete-filled steel tube after exposure to elevated temperature," Materials and Design, vol. 136, pp. 103-118, 2017.

[24] J. Wang, J. Zhang, and D. Cao, "Pore characteristics of recycled aggregate concrete and its relationship with durability under complex environmental factors," Construction and Building Materials, vol. 272, Article ID 121642, 2021.

[25] Y. C. Tang, L. J. Li, and W. X. Feng, "Seismic performance of recycled aggregate concrete-filled steel tube columns," Journal of Constructional Steel Research, vol. 133, pp. 112-124, 2017.

[26] S. Manzi, C. Mazzotti, and M. C. Bignozzi, "Self-compacting concrete with recycled concrete aggregate: study of the longterm properties," Construction and Building Materials, vol. 157, pp. 582-590, 2017.

[27] A. A. M. Al-Shaar and M. T. Gögüuss, "Flexural behavior of lightweight concrete and self-compacting concrete-filled steel tube beams," Journal of Constructional Steel Research, vol. 149, pp. 153-164, 2018.

[28] M. Mahgub, A. Ashour, D. Lam, and X. Dai, "Tests of selfcompacting concrete filled elliptical steel tube columns," ThinWalled Structures, vol. 110, pp. 27-34, 2017.

[29] Y. C. Tang, L. J. Li, W. X. Feng, F. Liu, and M. Zhu, "Study of seismic behavior of recycled aggregate concrete-filled steel tubular columns," Journal of Constructional Steel Research, vol. 148, pp. 1-15, 2018.

[30] GB/T2281-2010, Metallic Materials - Tensile Testing-Part 1: Method of Test at Room Temperature, Standards Press of China, Beijing, China, 2010.

[31] Y. B. He, A. L. Xiao, and Y. Huang, "Study on the ultimate bearing capacity of axially loaded steel tubular slender columns filled with steel-reinforced concrete," Building Structure, vol. 39, no. 6, pp. 29-33, 2009.

[32] Y. F. Yang and L. H. Han, "Experimental behaviour of recycled aggregate concrete filled steel tubular columns," Journal of Constructional Steel Research, vol. 62, pp. 13101324, 2006.

[33] Z. Lai and A. H. Varma, "Noncompact and slender circular CFT members: experimental database, analysis, and design," Journal of Constructional Steel Research, vol. 106, pp. 220-233, 2015.

[34] L. H. Han, L. Q. Zheng, S. H. He, and Z. Tao, "Tests on curved concrete filled steel tubular members subjected to axial compression," Journal of Constructional Steel Research, vol. 67, no. 6, pp. 965-976, 2011.

[35] X. G. Zhang, Z. P. Chen, J. Y. Xue, and Y. Su, "Experimental study and mechanical behavior analysis of recycled aggregate concrete filled steel tubular long columns under axial compression," Journal of Building Structures, vol. 33, no. 9, pp. 12-20, 2012.

[36] Y. H. Wu, Y. P. Fang, W. X. Feng, and Y. Cai, “Experimental research on mechanical behavior of recycled aggregate concrete filled circular steel tubular long columns under axial compression loading," Journal of Nanchang University, vol. 37, no. 1, pp. 27-33, 2015.

[37] GB50936-2014, Technical Code for concrete Filled Steel Tubular Structures, Standards Press of China, Beijing, China, 2014.
[38] ANSI/AISC-360-16, Specification for Structural Steel Buildings (ANSI/AISC 360-16), American Institute of steel construction, Chicago, American, 2016.

[39] AIJ-SRC-2001, The Standard for Structure Calculation of Steel Reinforced concrete Structure, Architectural Institute of Japan, Tokyo, Japan, 2001.

[40] Eurocode4, Design of Composite Steel and Concrete Structures, European Committee for Standardization, Brussels, Belgium, 2004. 